\title{
RELAÇÕES HÍDRICAS E SOLUTOS ORGÂNICOS EM PLANTAS JOVENS DE Jatropha curcas L. SOB DIFERENTES REGIMES HÍDRICOS
}

\author{
WATER RELATIONS AND ORGANIC SOLUTES IN YOUNG PLANTS OF \\ Jatropha curcas L. UNDER DIFFERENT WATER REGIMES
}

\author{
Adenilda Ribeiro de Moura ${ }^{1}$ Rejane Jurema Mansur Custódio Nogueira ${ }^{2}$ \\ José Antônio Aleixo da Silva ${ }^{3}$ Tarcísio Viana de Lima ${ }^{4}$
}

\begin{abstract}
RESUMO
O objetivo deste trabalho foi avaliar as relações hídricas e os solutos orgânicos em plantas de Jatropha curcas L. submetidas a deficit hídrico e cultivadas em casa de vegetação. O delineamento foi o inteiramente casualizado, com quatro tratamentos hídricos $\left(\mathrm{T}_{1}-100 \%, \mathrm{~T}_{2}-80 \%, \mathrm{~T}_{3}-60 \%\right.$ e $\mathrm{T}_{4}-40 \%$ da Capacidade de Pote) e seis repetições, durante 120 dias. Foi avaliado o potencial hídrico foliar ( $\Psi$ f), teor relativo de água, teores de clorofila $a, b$ e total, carotenoides e a estimativa desses pigmentos pelo medidor de clorofila (SPAD). Para a avaliação bioquímica foram quantificados os teores de carboidratos, proteínas, aminoácidos e prolina nas folhas aos 60, 90 e 120 dias, e no final do experimento foram avaliados os mesmos solutos nas raízes. Houve diferença significativa entre os tratamentos para If nas três épocas de avaliação e entre os tratamentos. As plantas com $60 \%$ e $40 \% \mathrm{CP}$ apresentaram valores mais negativos em relação às plantascontrole ao meio-dia. Aos 120 dias, o tratamento $\mathrm{T}_{4}$ apresentou uma redução de $22,2 \%$ no teor relativo de água em relação ao controle. Os carotenoides, aos 120 dias, oscilaram entre 0,29 a 0,39 mg/g MF. Os aminoácidos e carboidratos aumentaram nas folhas do tratamento com $80 \%$ Capacidade de Pote aos 120 dias de diferenciação hídrica. Aos 60, 90 e 120 dias, a clorofila $a$ apresentou um aumento no $\mathrm{T}_{4}$ em relação ao controle. Os teores de clorofila pelo o Índice SPAD variaram de $(26,1$ a 34,5). Os resultados obtidos sugerem que a Jatropha curcas é uma espécie tolerante à seca e com grandes potencialidades econômicas para o semiárido brasileiro.
\end{abstract}

Palavras-chave: deficit hídrico; osmorregulação; parâmetros fisiológicos.

\begin{abstract}
The objective of this study was to evaluate water and organic solutes in plants of Jatropha curcas L. exposed to water deficit and grown in a greenhouse. The design was completely randomized with four water treatments $(-100 \% \mathrm{~T} 1, \mathrm{~T} 2-80 \%, \mathrm{~T} 3-\mathrm{T} 4$ and $60 \%-40 \%$ of pot capacity) and six replicates for 120 days. We evaluated the leaf water potential ( $\Psi f)$, relative water content, content of chlorophyll a, b and total carotenoids and these pigments estimated by chlorophyll meter (SPAD). For biochemical evaluation were quantified levels of carbohydrates, proteins, amino acids and proline in the leaves at 60,90 and 120 days, and at the end of the experiment, the same solutes in roots. There were significant differences between treatments for $\Psi f$ the three evaluation periods and between treatments. Plants with $60 \%$ and $40 \%$

1 Bióloga, MSc., Diretora de Ensino da Educação à Distância, Instituto Federal de Ciência e Tecnologia de Pernambuco, Av. Professor Luiz Freire, 500, Cidade Universitária, CEP 50740-540, Recife (PE), Brasil. adenildamoura@gmail.com

2 Bióloga, Dr ${ }^{\mathrm{a}}$., Professora Associada IV do Departamento de Biologia, Universidade Federal Rural de Pernambuco, Rua Dom Manoel de Medeiros, s/n, Dois Irmãos, CEP 52171-900, Recife (PE), Brasil. rjmansur1@gmail.com

3 Engenheiro Agrônomo, Ph.D., Professor Associado IV do Departamento de Ciência Florestal, Universidade Federal Rural de Pernambuco, Rua Dom Manoel de Medeiros, s/n, Dois Irmãos, CEP 52171-900, Recife (PE), Brasil.jaaleixo@uol.com.br

4 Engenheiro Florestal, Dr., Professor Associado I do Departamento de Ciência Florestal, Universidade Federal Rural de Pernambuco, Rua Dom Manoel de Medeiros, s/n, Dois Irmãos, CEP 52171-900, Recife (PE), Brasil. vianadelima.tvianalima@gmail.com
\end{abstract}

Recebido para publicação em 28/05/2010 e aceito em 20/08/2014 
CP showed more negative compared to control plants at noon. After 120 days treatment T4 decreased by 22 $2 \%$ in relative water content compared to control. The carotenoids at 120 days ranged from 0.29 to $0.39 \mathrm{mg}$ / g MF. Amino acids and carbohydrates in the leaves increased with $80 \%$ of treatment capacity pot to 120 days of differentiation water. At 60,90 and 120 days, chlorophyll a showed an increase in Q4 compared to control. The content of chlorophyll by the SPAD index ranged from (26.1 to 34.5). The results suggest that Jatropha curcas is a drought tolerant species and with great economic potential for the Brazilian semiarid region.

Keywords: drought; osmoregulation; physiological parameters.

\section{INTRODUÇÃO}

O pinhão-manso (Jatropha curcas L.) vem se destacando no cenário mundial por ser uma espécie oleaginosa promissora para a produção de biodiesel ecologicamente sustentável (ARRUDA et al., 2004). Esta espécie chega a produzir frutos ricos em óleo já no primeiro ano de cultivo (em cultivos comerciais, a produtividade média é de $5 \mathrm{t} / \mathrm{ha}$ ) (SATO et al., 2009). Quanto à produção de óleos, a extração de suas sementes é bastante promissora, justamente por apresentar 53 a $79 \%$ do peso do fruto e com um teor de óleo alto, que varia de entre 33 a 38\% (OPENSHAW, 2000; ARRUDA et al., 2004).

É considerada uma espécie vegetal que pode proporcionar efeitos positivos sobre o desenvolvimento socioeconômico na região semiárida do nordeste brasileiro (SATURNINO et al., 2005). No entanto, pouco se conhece sobre os mecanismos fisiológicos que essa espécie utiliza com relação à tolerância seca.

Algumas plantas, sob condições de baixa disponibilidade hídrica, perdem a turgescência celular, levando à redução da condutância estomática e do potencial da água da folha (NOGUEIRA; SANTOS, 2000). Pesquisas demonstram que, quando as plantas são expostas ao deficit hídrico, podem ocorrer alterações metabólicas, como por exemplo, a conversão do amido em carboidratos solúveis tais como sacarose, glicose, frutose, visando o equilíbrio osmótico da célula (AZEVEDO NETO, 2005). Outro exemplo é o acúmulo de prolina, um aminoácido que contribui para o processo de osmorregulação (BATES et al., 1973; SILVA et al., 2004). Segundo Egert e Tevini (2002), plantas quando submetidas ao estresse hídrico podem reduzir os teores de pigmentos fotossintéticos devido aos danos oxidativos, no entanto, as plantas protegem sintetizando antioxidantes tais como carotenoides, favorecendo o aumentado do teor de enzimas dentre elas as peroxidases.
Em face da escassez de trabalhos sobre os mecanismos fisiológicos utilizados pelo pinhão-manso para tolerar ambientes com baixa disponibilidade hídrica, o presente trabalho teve por objetivo avaliar as relações hídricas, teores de pigmentos fotossintéticos e o acúmulo de solutos orgânicos osmoticamente ativos em mudas de pinhão-manso (Jatropha curcas L.) submetidas a diferentes disponibilidades hídricas no solo.

\section{MATERIAL E MÉTODOS}

A pesquisa foi conduzida em casa de vegetação do Laboratório de Fisiologia Vegetal do Departamento de Biologia da Universidade Federal Rural de Pernambuco - UFRPE, no período de 120 dias. As sementes foram coletadas no campo experimental do Centro de Ciências Agrárias da Universidade Federal de Alagoas - UFAL, postas para germinar em bandejas com capacidade para $17 \mathrm{Kg}$ de solo, contendo como substrato areia lavada.

Aos 30 dias após a germinação, foram selecionadas plântulas com porte uniforme, de boa sanidade e com quatro folhas completamente expandidas. Posteriormente, as mesmas foram transferidas para vasos de polietileno contendo $11 \mathrm{Kg}$ de solo, classificado como Neossolo Regolítico, procedente da Estação Experimental do IPA (Empresa Pernambucana de Pesquisa Agropecuária), no município de Caruaru - PE, coletado nas profundidades de $0-20$ e $20-40 \mathrm{~cm}$, colocados nos vasos em camadas sobrepostas para simular as condições naturais da Caatinga, no entanto, optou-se por não adubar o solo.

A análise físico-química do solo (Tabela 1) foi realizada no Departamento de Agronomia, Laboratório de Fertilidade do Solo da Universidade Federal Rural de Pernambuco. As plântulas foram mantidas na capacidade de pote (capacidade máxima de retenção de água pelo 
solo - CP), com regas diárias, durante 30 dias para aclimatação. Após esse período, deu-se início a aplicação dos tratamentos hídricos.

O delineamento experimental adotado foi inteiramente casualizado, correspondendo a quatro tratamentos hídricos $\mathrm{T}_{1-} 100 \%, \mathrm{~T}_{2-} 80 \%, \mathrm{~T}_{3-} 60 \%$ e $\mathrm{T}_{4-}$ $40 \%$ da CP e seis plântulas por repetição, segundo a metodologia proposta por Souza et al. (2000). As plantas foram regadas diariamente e a manutenção dos diferentes níveis de água foi efetuada pela pesagem dos vasos e reposição da água perdida pela evapotranspiração.

A superfície do vaso foi coberta com plástico para evitar a excessiva evaporação da água contida no solo. $\mathrm{O}$ potencial hídrico foliar

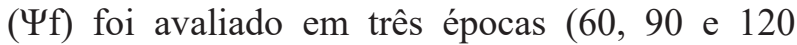
dias após a diferenciação) em dois horários de avaliação, na antemanhã (4h) e ao meio-dia (12h). Com o uso da Câmara de Pressão de Scholander, segundo Scholander et al. (1965). Para as análises do potencial hídrico foliar, foram selecionadas as folhas localizadas no terço médio da planta.

O Teor Relativo de Água (TRA) foi mensurado nos mesmos horários do potencial hídrico foliar, seguindo a metodologia de Weatherley (1950). Foram retiradas seis amostras de discos foliares com aproximadamente $0,5 \mathrm{~cm}$ de diâmetro nas mesmas folhas utilizadas para o potencial hídrico. Os discos foram pesados para a determinação do peso da massa fresca e em seguida, os mesmos foram colocados em placas de Petri, imersos em água deionizada. Após 24h, foram novamente pesados para a obtenção do peso da massa túrgida e, logo depois acondicionados em sacos de papel e levados à estufa de circulação forçada de ar a $65^{\circ} \mathrm{C}$ para determinação do peso da massa seca. A partir dos pesos da matéria fresca $(\mathrm{PF})$, matéria túrgida (PT) e matéria seca (PS), foi calculado o teor relativo de água de acordo com a fórmula $T R A=[(P F-P S / P T-P S)] \times 100$.
Para a determinação dos solutos orgânicos foi retirado $1 \mathrm{~g}$ do limbo foliar das folhas localizadas abaixo do terço médio da planta nas três épocas de avaliação (60, 90 e 120 dias). No final do experimento foi retirado $1 \mathrm{~g}$ das raízes adventícias para estimar os solutos orgânicos.

A concentração de carboidratos foi determinada a $490 \mathrm{~nm}$, pelo método do fenol-ácido sulfúrico (DUBOIS et al., 1956) utilizando-se D-(+)glucose como padrão e as concentrações foram expressas em $\mathrm{mmol} / \mathrm{g}$ de matéria fresca das folhas. A concentração de prolina livre foi determinada pelo método da ninidrina e ácido fosfórico (BATES et al., 1973), utilizando-se a prolina como padrão, as concentrações foram expressas em $\mathrm{mmol} / \mathrm{g}$ matéria fresca das folhas.

A determinação de proteína, foi realizada pelo método da ligação ao corante comassie brilliant blue (BRADFORD, 1976), utilizando-se como padrão albumina sérica bovina e as concentrações foram expressas em $\mathrm{mg} / \mathrm{g}$ de matéria fresca. Os aminoácidos foram analisados pelo método de ninidrina (YEMM; COCKING, 1955), utilizandose glicina como padrão. As concentrações foram expressas em $\mathrm{mmol} / \mathrm{g}$ matéria fresca das folhas.

Paralelamente o teor de clorofilas $a, b$ e carotenoides foi quantificado de acordo com a metodologia de Lichetenthaler e Buschamann (2001), nos comprimentos de onda $645 \mathrm{~nm}, 663 \mathrm{~nm} \mathrm{e}$ 470 nm, com o uso do espectrofotômetro Biospectro (modelo SP-220). Foram cortados $100 \mathrm{mg}$ de matéria fresca de folhas +2 de cada repetição. Em seguida, colocadas em tubos de ensaio rosqueados, cobertos com papel alumínio para evitar passagem de luz, contendo $10 \mathrm{~mL}$ de álcool a $95 \%$. Os dados foram calculados pelas fórmulas descritas abaixo e, os resultados expressos em miligrama de clorofila por grama de tecido fresco $(\mathrm{mg} / \mathrm{g}): \mathrm{Cl}_{\text {total }}(\mathrm{mg} / \mathrm{L})=$ $17,3 \times \mathrm{A}_{645}+7,18 \times \mathrm{A}_{663}, \mathrm{Cl}_{\mathrm{a}}(\mathrm{mg} / \mathrm{L})=12,21 \times \mathrm{A}_{663}-$ $2,81 \times \mathrm{A}_{645}, \mathrm{Cl}_{\mathrm{b}}(\mathrm{mg} / \mathrm{L})=20,13 \times \mathrm{A}_{645}-5,03 \times \mathrm{A}_{663}$,

TABELA 1: Características químicas do Neossolo Regolítico coletado na estação Experimental de Caruaru-IPA, usado no experimento.

TABLE 1: Chemical characteristics of Entisol collected at the Experimental Station of Caruaru-IPA, used in the experiment.

\begin{tabular}{|c|c|c|c|c|c|c|c|}
\hline \multirow{2}{*}{ Profundidade $(\mathrm{cm})$} & $\mathrm{pH}$ & $\mathrm{P}$ & \multirow{2}{*}{$\mathrm{Na}^{+}$} & \multirow{2}{*}{$\mathrm{K}^{+}$} & $\mathrm{Ca}^{+2}+\mathrm{Mg}^{+2}$ & \multirow{2}{*}{$\mathrm{Ca}^{+2}$} & \multirow{2}{*}{$\mathrm{Al}^{+3}$} \\
\hline & Água-1:2,5 & $\left(\mathrm{mg} / \mathrm{dm}^{3}\right)$ & & & $\left(\mathrm{cmol} / \mathrm{dm}^{3}\right)$ & & \\
\hline $0-20$ & 5,90 & 7 & 2,65 & 0,07 & 7,8 & 1,4 & 0,1 \\
\hline $20-40$ & 6,50 & 9 & 1,47 & 0,06 & 6,35 & 1,35 & 0,1 \\
\hline
\end{tabular}


Carotenoides $(\mathrm{mg} / \mathrm{L})=(1000 \times \mathrm{A} 470-3,27[\mathrm{Cl} \mathrm{a}]$ $-104[\mathrm{Cl} \mathrm{b}])$.

Para o modelo estatístico aplicado neste trabalho utilizou-se um delineamento no qual a proposta foi uma sequência de medidas ao longo do tempo, caracterizando uma análise multivariada de medidas repetidas. As análises estatísticas foram realizadas utilizando-se o programa estatístico SAS - Statistical Analysis System (SAS INSTITUTE, 2002) e as médias comparadas pelo teste de Tukey a $5 \%$ de probabilidade.

\section{RESULTADOS E DISCUSSÃO}

Os resultados para o potencial hídrico foliar em plantas de Jatropha curcas, nas três épocas de avaliação, permitem observar o comportamento das espécies quando submetidas a diferentes níveis de água no solo. Aos 60, 90 e 120 dias de tratamentos hídricos, as plantas cultivadas com 80, 60 e $40 \%$ $\mathrm{CP}$ apresentaram reduções significativas no $\Psi f$ em relação às plantas do tratamento-controle no período da antemanhã (Figura 1). Às 12 horas, foram verificadas reduções apenas nos tratamentos com 60 e $40 \%$ CP. Na medida em que se prolongou o estresse hídrico aos 120 dias, foi verificada uma contínua redução no $\Psi$ f nas plantas com 60 e 40 $\%$ CP. Os valores mais negativos do potencial hídrico foliar foram observados ao meio-dia nas plantas com 60 e $40 \% \mathrm{CP}$, que apresentaram valores médios na ordem de -1,6 e -1,4 MPa, aos 60 dias, $-2,4$ e $-2,5 \mathrm{MPa}$, aos 90 e 120 dias valores de $-3,3$ e $-3,5 \mathrm{MPa}$, respectivamente. Aos 90 e 120 dias de restrição hídrica já eram visíveis sintomas de perda de turgescência e abscisão foliar.

De maneira geral, os resultados comprovam a importância de avaliar o potencial hídrico foliar no horário da antemanhã e ao meio-dia, tendo em vista que as avaliações feitas na antemanhã revelam que o potencial hídrico da planta tende a se igualar ao potencial hídrico do solo, podendo indicar uma estratégia de ajustamento osmótico. Ao meio-dia, os valores do potencial hídrico apresentaram valores mais negativos por ser o horário de maior demanda evaporativa para a espécie, a qual está condicionada à restrição hídrica, consequentemente, acentua os efeitos do deficit de água no solo, levando a planta a promover uma redução do seu potencial hídrico (TAIZ; ZEIGER, 2009).

Quanto menor for a quantidade de água no solo mais negativo deve ser o potencial hídrico desenvolvido pelas raízes, principalmente no horário

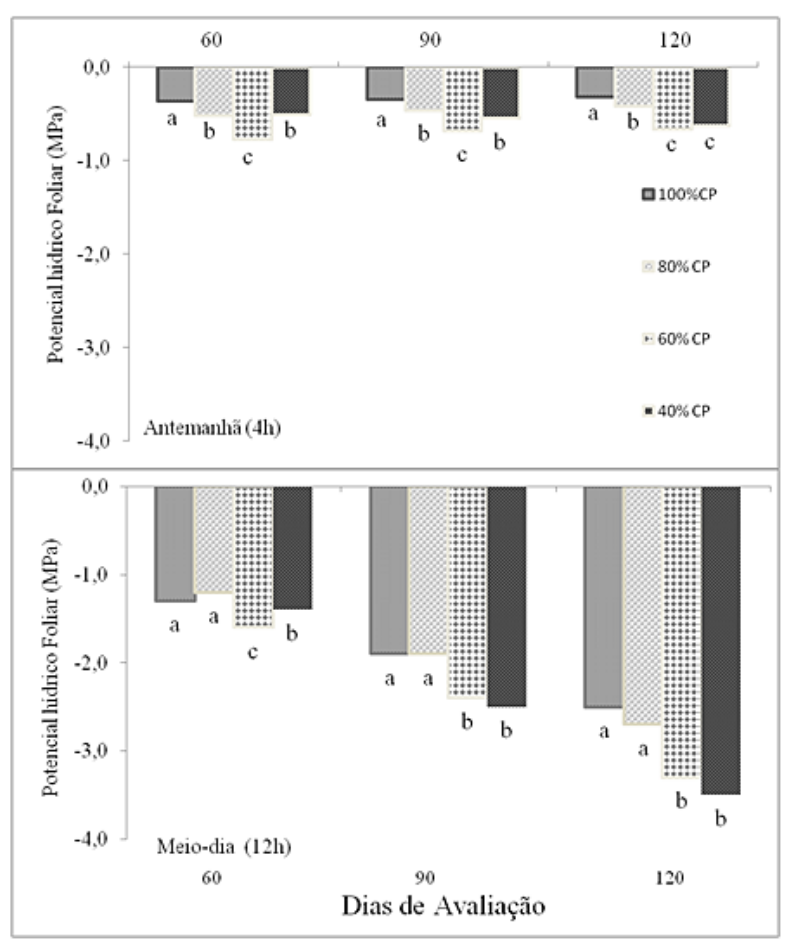

FIGURA 1: Potencial hídrico foliar(MPa) em plantas jovens de Jatropha curcas submetida ao deficit hídrico às $4 \mathrm{~h}$ (antemanhã) e às $12 \mathrm{~h}$ (meio-dia) aos 60, 90 e 120 dias de avaliação hídrica. Médias seguidas de mesma letra não diferiram entre si dos tratamentos hídricos, pelo teste de Tukey $(\mathrm{P}<0,05)$.

FIGURE 1: Leaf water potential (MPa) in young plants of Jatropha curcas subjected to water deficit to 4 hours (before dawn) and $12 \mathrm{~h}$ (noon) at 60,90 and 120 days of water evaluation. Means followed by same letter do not differ from water treatments, the Tukey test $(\mathrm{P}<0.05)$.

do meio-dia, quando a transpiração apresenta valores elevados e a pressão negativa no xilema apresenta valores menores da absorção de água pela planta (LARCHER, 2006). A literatura reporta que com valores iguais ou abaixo de -1,5 MPa no solo, as plantas entram num processo chamado de murcha permanente. Porém, existem algumas espécies que apresentam um alto grau de tolerância à falta de água, podendo chegar a $-6,0 \mathrm{MPa}$, o que representa um potencial letal para essas espécies (PIMENTEL, 2004).

Resultados obtidos por Souza (2008) em três cultivares de algodoeiro herbáceo mostraram que com o prolongamento do estresse aos 45 dias de 
diferenciação hídrica ocorreu uma queda do $\Psi f$ nos dois horários de avaliação (antemanhã e ao meiodia), atingindo valores mais altos -1,08 MPa para as cvs. $7 \mathrm{MH}$ e cedro com $100 \%$ da CP e mais baixos $-3,05 \mathrm{MPa}$ para cv. cedro com $25 \%$ da CP.

Quando o potencial hídrico foliar fica mais negativo é porque ocorreu uma redução no potencial osmótico. Essa redução pode ser devida ao aumento da concentração de solutos osmoticamente ativos e de íons no vacúolo para manter o potencial hídrico e a turgescência da célula próxima do nível ótimo (NEPOMUCENO et al., 2001).

$\mathrm{O}$ teor relativo de água nas plantas do pinhão-manso cultivadas em casa de vegetação variou de $76,2 \%$ a $98,8 \%$, durante o período experimental de 120 dias. Diferenças significativas entre os tratamentos hídricos só foram verificados a partir dos 120 dias, no horário das $12 \mathrm{~h}$, no tratamento com $40 \%$ CP. Neste tratamento, verificou-se uma redução significativa na ordem de $22,3 \%$ em relação às plantas-controle (Tabela 2). Embora o potencial hídrico foliar tenha reduzido, não ocorreu redução do teor relativo de água (TRA), demonstrando que as folhas mantiveram a sua turgescência.

Isso pode ser explicado pelo acúmulo de solutos orgânicos compatíveis, capazes de provocar redução no potencial osmótico, sem, contudo, perder água para o meio. Em relação ao acúmulo de solutos orgânicos, as plantas de Jatropha curcas submetidas à deficiência hídrica apresentaram reduções nos teores de aminoácidos e carboidratos à medida que o estresse foi mais intenso, enquanto que os teores de proteínas e prolina não apresentaram diferenças significativas.

Aos 60 dias de diferenciação hídrica, as concentrações de aminoácidos nas folhas de Jatropha curcas variaram de 0,15 a $0,29 \mu \mathrm{mol} / \mathrm{g}$ MF. Porém, nesta época de avaliação, não houve diferença significativa entre os tratamentos hídricos. Os teores de aminoácidos nas folhas dos tratamentos com $60 \%$ e $40 \%$ CP, aos 90 dias de diferenciação hídrica, apresentaram valores médios de 0,11 e $0,09 \mu \mathrm{mol} / \mathrm{g}$ MF. Os tratamentos com $60 \%$ e $40 \%$ CP apresentaram uma redução de $60,3 \%$ e $53 \%$, respectivamente, em relação ao tratamento-controle (Figura 2).

Embora não tenham ocorridos diferenças estatísticas significativas entre os tratamentos avaliados em cada época estudada, detectou-se para os carboidratos, que as plantas foram mais sensíveis ao estresse hídrico aos 90 dias de diferenciação hídrica (Figura 3).

$\mathrm{O}$ deficit hídrico pode afetar as concentrações de carboidratos, por alterar, basicamente, a eficiência com que os fotoassimilados são convertidos para o desenvolvimento de partes novas na planta.

Com relação aos teores de proteínas em folhas de Jatropha curcas submetidas à deficiência hídrica, observou-se que não houve diferenças significativas entres os tratamentos estudados nas três épocas de avaliação (Figura 4). Resultados semelhantes para os níveis de proteínas em plantas de gergelim foram encontrados por Souza et al. (2000), quando submetidas a 16 dias de deficiência hídrica.

Aos 60 dias de avaliação do deficit hídrico, observou-se que os teores de prolina livre nas folhas de Jatropha curcas variaram de 0,31 a $0,38 \mu \mathrm{mol} / \mathrm{g}$ MF; havendo um acréscimo médio aos 90 dias de

TABELA 2: Teor relativo de água TRA (\%) em plantas de Jatropha curcas aos 60, 90 e 120 dias de avaliação hídrica, sob diferentes tratamentos hídricos.

TABLE 2: TRA relative water content (\%) in plant Jatropha curcas at 60, 90 and 120 days of water assessment under different water treatments.

\begin{tabular}{ccccccc}
\hline \multirow{2}{*}{ Tratamentos Hídricos (\%) } & \multicolumn{2}{c}{60 dias } & \multicolumn{2}{c}{90 dias } & \multicolumn{2}{c}{120 dias } \\
\cline { 2 - 7 } & $4 \mathrm{~h}$ & $12 \mathrm{~h}$ & $4 \mathrm{~h}$ & $12 \mathrm{~h}$ & $4 \mathrm{~h}$ & $12 \mathrm{~h}$ \\
\hline $100 \% \mathrm{CP}$ & $89,6 \mathrm{a}$ & $91,1 \mathrm{a}$ & $92,8 \mathrm{a}$ & $89,8 \mathrm{a}$ & $90,8 \mathrm{a}$ & $98,8 \mathrm{a}$ \\
$80 \% \mathrm{CP}$ & $92,4 \mathrm{a}$ & $90,3 \mathrm{a}$ & $92,1 \mathrm{a}$ & $83,3 \mathrm{ab}$ & $95,1 \mathrm{a}$ & $94,4 \mathrm{ab}$ \\
$60 \% \mathrm{CP}$ & $91,5 \mathrm{a}$ & $88,2 \mathrm{a}$ & $91,5 \mathrm{a}$ & $84,2 \mathrm{a}$ & $79,3 \mathrm{a}$ & $88,9 \mathrm{ab}$ \\
$40 \% \mathrm{CP}$ & $92,6 \mathrm{a}$ & $91,7 \mathrm{a}$ & $93,5 \mathrm{a}$ & $76,2 \mathrm{ab}$ & $85,5 \mathrm{a}$ & $79,8 \mathrm{~b}$ \\
\hline $\mathrm{CV} \%$ & 5,12 & 5,11 & 5,05 & 12,34 & 12,70 & 12,89 \\
\hline
\end{tabular}

Em que: Médias seguidas pela mesma letra minúscula nas colunas, não diferem significativamente pelo teste de Tukey $(\mathrm{P}<0,05)$. 


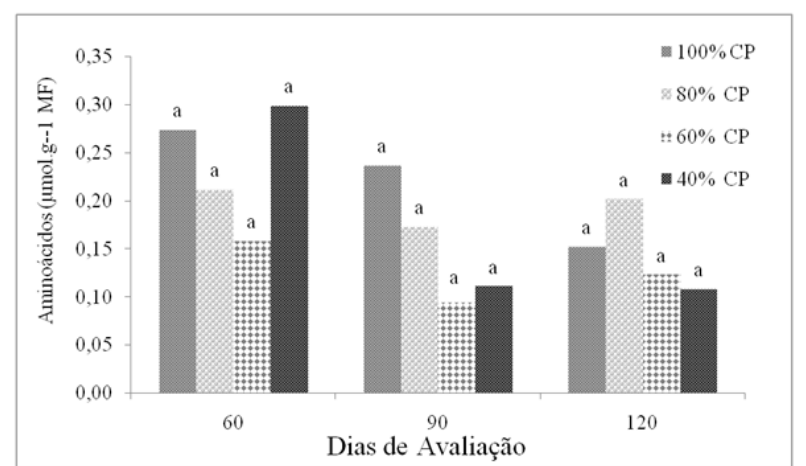

FIGURA 2: Valores médios dos teores de aminoácidos em plantas jovens de Jatropha curcas aos 60, 90 e 120 dias de avaliação hídrica. Médias seguidas de mesma letra não diferiram entre si nos tratamentos hídricos, pelo teste de Tukey $(\mathrm{P}<0,05)$.

FIGURE 2: Average values of the amino acid contents in seedlings of Jatropha curcas at 60,90 and 120 days of water assessment. Means followed by same letter do not differ in water treatments, the Tukey test $(\mathrm{P}<0.05)$.

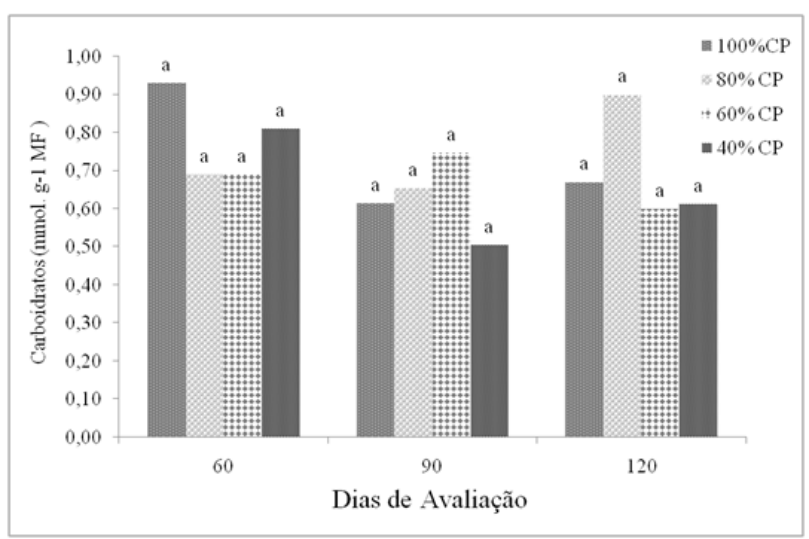

FIGURA 3: Valores médios dos teores de carboidratos em plantas jovens de Jatropha curcas, aos 60, 90 e 120 dias de avaliação hídrica. Médias seguidas de mesma letra não diferiram entre si nos tratamentos hídricos, pelo teste de Tukey $(\mathrm{P}<0,05)$.

FIGURE 3: Average values of the carbohydrates in seedlings of Jatropha curcas subjected to water deficit. Means followed by same letter do not differ in water treatments, the Tukey test $(\mathrm{P}<0.05)$.

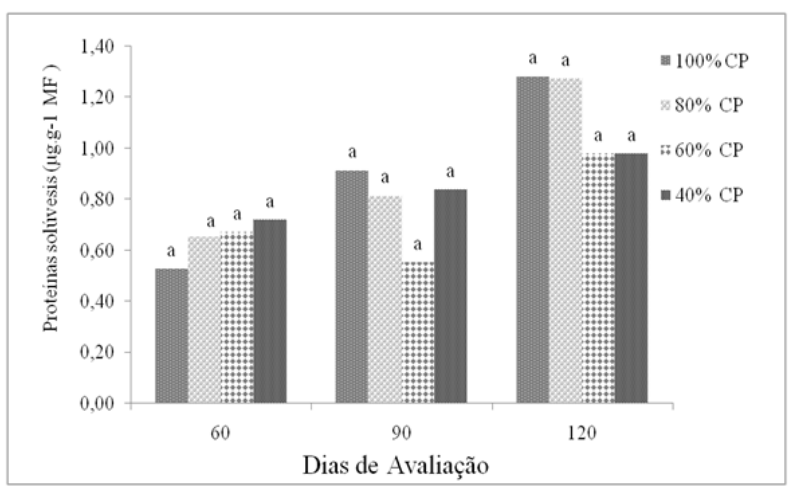

FIGURA 4: Valores médios dos teores de proteínas totais em plantas jovens de Jatropha curcas, aos 60, 90 e 120 dias de avaliação hídrica. Médias seguidas de mesma letra não diferiram entre si nos tratamentos hídricos, pelo teste de Tukey $(\mathrm{P}<0,05)$.

FIGURE 4: Mean values of total protein levels in young plants of Jatropha curcas, 60, 90 and 120 days of water assessment. Means followed by same letter do not differ in water treatments, the Tukey test $(\mathrm{P}<0.05)$.

0,34 a $0,58 \mu \mathrm{mol} / \mathrm{g}$ MF. Já, aos 120 dias, constatouse que os teores de prolina variaram de 0,54 a 0,76 $\mu \mathrm{mol} / \mathrm{g}$ MF. Embora essas variações na concentração desse soluto tenham revelado acúmulo nas folhas da espécie estudada, durante cada período analisado, não foram detectadas diferenças significativas entre os tratamentos testados (Figura 5).

Sabe-se que a prolina tem a função osmoprotetora quando a planta está sob influência de estresse hídrico ao longo do tempo. Carvalho (2005), estudando teores de prolina em plantas de Tanacetum parthenium (L.) desenvolvidas em substrato com vários teores de umidade, detectou variações de 9 a $14 \mu \mathrm{g} / \mathrm{g}$ MF nos tratamentos com $100 \%, 90 \%$ e $70 \%$ da $\mathrm{CP}$, enquanto que as plantas mantidas em substrato a $50 \%$ da $\mathrm{CP}$ apresentaram valores de 27 a $32 \mu \mathrm{g} / \mathrm{g}$ MF.

De forma geral, observou-se que o deficit hídrico não influenciou no acúmulo de solutos orgânicos nas folhas entre os tratamentos para cada período analisado. No entanto, as raízes de Jatropha curcas apresentaram, no período de 120 dias, maiores concentrações dos solutos carboidratos e proteínas no tratamento com $60 \%$ $\mathrm{CP}$, e de aminoácidos no tratamento com $40 \% \mathrm{CP}$ 


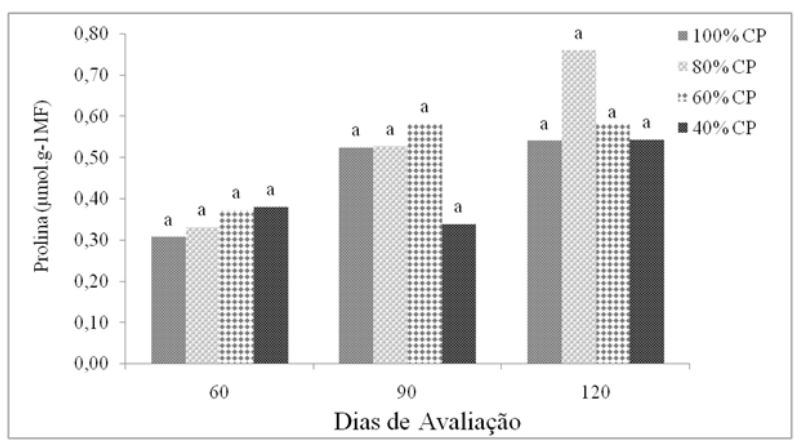

FIGURA 5: Valores médios dos teores de prolina em plantas jovens de Jatropha curcas, aos 60, 90 e 120 dias de avaliação hídrica. Médias seguidas de mesma letra não diferiram entre si nos tratamentos hídricos, pelo teste de Tukey $(\mathrm{P}<0,05)$.

FIGURE 5: Mean values of proline contents in seedlings of Jatropha curcas, 60, 90 and 120 days of water assessment. Means followed by same letter do not differ in water treatments, the Tukey test $(\mathrm{P}<0.05)$.

(Tabela 3). Tal comportamento, estrategicamente, pode ser considerado um mecanismo de adaptação ou tolerância à deficiência hídrica em plantas estressadas.

Entretanto, esses assimilados derivados da fotossíntese são investidos no crescimento de raízes para induzi-las a explorar maior área de solo em busca de água, cuja disponibilidade, segundo Silva (2009), é maior em horizontes mais profundos do perfil em solos secos.

Com relação aos teores de prolina livre presente nas raízes de pinhão-manso, observouse, no período de 120 dias, que os diferentes tratamentos hídricos empregados não alteraram significativamente as concentrações desse soluto nesse órgão (Tabela 3). Tal resultado demonstra que, apesar desta espécie apresentar redução no potencial hídrico foliar nos tratamentos mais estressados, nos horários da antemanhã (4 horas) e ao meio-dia, verificou-se baixa sensibilidade das plantas quando submetidas ao deficit hídrico. Este comportamento é considerado atípico quando comparado com resultados obtidos por vários autores (NOGUEIRA et al., 2001; SARKER; HARA; UEMURA, 2005; MARTINS, 2008) para outras espécies estudadas sob tais condições.

Hanson (1980) afirma que o teor de prolina livre em plantas submetidas à deficiência hídrica pode aumentar de 20 a 100 vezes em relação às plantas sob condições hídricas normais.

Segundo Subbarão (2000), o acúmulo dos aminoácidos e açúcares livres em folhas e raízes, pode ser decorrente da restrição à síntese de proteínas e da hidrólise das reservas de amido, bem como de distúrbios causados pela deficiência de água nos tecidos do floema, reduzindo a sua translocação para outros órgãos. As plantas se ajustam osmoticamente acumulando solutos orgânicos nas suas raízes que pode ser explicado pelo baixo potencial hídrico foliar da mesma.

$\mathrm{O}$ deficit hídrico não afetou de forma significativa os pigmentos fotossintéticos nas duas primeiras épocas de avaliação (Tabela 4). Os valores médios para os teores de clorofila variaram de 0,65 a $0,91 \mathrm{mg} / \mathrm{gMF}$ para a clorofila $a$ e de 0,27 a 0,91 $\mathrm{mg} / \mathrm{g}$ MF para a clorofila $b$, aos 60 dias de avaliação. Aos 120 dias notou-se um aumento da clorofila $a$ nas plantas com 60 e $40 \%$ da CP. A clorofila $b$ não apresentou diferença significativa entre os tratamentos durante as três épocas de avaliação.

A relação da clorofila $a / b$ não apresentou

TABELA 3: Teores de carboidratos solúveis totais, proteínas solúveis, aminoácidos livres e prolina livre em raízes de Jatropha curcas, aos 120 dias de avaliação hídrica.

TABLE 3: Levels of total soluble carbohydrates, soluble proteins, amino acids and free proline in roots of Jatropha curcas, at 120 days of water assessment.

\begin{tabular}{ccccc}
\hline $\begin{array}{c}\text { Tratamentos } \\
\text { Hídricos }\end{array}$ & $\begin{array}{c}\text { Carboidratos } \\
(\mathrm{mmol} / \mathrm{gMF})\end{array}$ & $\begin{array}{c}\text { Proteínas } \\
(\mathrm{mg} / \mathrm{g}) /(\mathrm{gMF})\end{array}$ & $\begin{array}{c}\text { Aminoácidos } \\
(\mu \mathrm{mol} / \mathrm{gMF})\end{array}$ & $\begin{array}{c}\text { Prolina } \\
(\mu \mathrm{mol} / \mathrm{gMF})\end{array}$ \\
\hline $100 \% \mathrm{CP}$ & $13,71 \mathrm{bc}^{*}$ & $13,28 \mathrm{~b}$ & $3,27 \mathrm{ab}$ & $0,31 \mathrm{a}$ \\
$80 \% \mathrm{CP}$ & $11,19 \mathrm{c}$ & $14,34 \mathrm{ab}$ & $1,40 \mathrm{~b}$ & $0,33 \mathrm{a}$ \\
$60 \% \mathrm{CP}$ & $32,12 \mathrm{a}$ & $19,71 \mathrm{a}$ & $5,62 \mathrm{ab}$ & $0,37 \mathrm{a}$ \\
$40 \% \mathrm{CP}$ & $19,25 \mathrm{~b}$ & $16,35 \mathrm{ab}$ & $5,84 \mathrm{a}$ & $0,37 \mathrm{a}$ \\
\hline
\end{tabular}

Em que: *Médias seguidas de mesmas letras nas colunas não diferem entre si pelo teste de Tukey $(\mathrm{P}<0,05)$ 
TABELA 4: Avaliação dos teores de clorofila $a, b, a / b$, carotenoides, clorofila total e índice de determinação do SPAD em plantas Jatropha curcas, aos 60, 90 e 120 dias de avaliação hídrica.

TABLE 4: Evaluation of chlorophyll a, b, a / b, carotenoids, chlorophyll and SPAD index determination in plants Jatropha curcas, 60, 90 and 120 days of water assessment.

\begin{tabular}{cccccccc}
\hline \multicolumn{7}{c}{ Teores de clorofila } \\
\hline $\begin{array}{c}\text { Dias } \\
\text { Avaliados }\end{array}$ & Tratamentos Hidrícos (\%) & $\mathrm{Cla}$ & $\mathrm{Cl} b$ & $\mathrm{Cl} a / b$ & Carot. & Cl Total & SPAD \\
\hline \multirow{2}{*}{60} & $100 \% \mathrm{CP}$ & $0,73 \mathrm{a}$ & $0,27 \mathrm{a}$ & $2,67 \mathrm{a}$ & $0,32 \mathrm{a}$ & $1,02 \mathrm{a}$ & $28,90 \mathrm{ab}$ \\
& $80 \% \mathrm{CP}$ & $0,69 \mathrm{a}$ & $0,27 \mathrm{a}$ & $2,49 \mathrm{a}$ & $0,29 \mathrm{a}$ & $0,92 \mathrm{a}$ & $27,50 \mathrm{ab}$ \\
& $60 \% \mathrm{CP}$ & $0,72 \mathrm{a}$ & $0,28 \mathrm{a}$ & $2,58 \mathrm{a}$ & $0,32 \mathrm{a}$ & $1,01 \mathrm{a}$ & $26,30 \mathrm{~b}$ \\
& $40 \% \mathrm{CP}$ & $0,91 \mathrm{a}$ & $0,42 \mathrm{a}$ & $2,33 \mathrm{a}$ & $0,39 \mathrm{a}$ & $1,33 \mathrm{a}$ & $30,90 \mathrm{a}$ \\
\hline \multirow{2}{*}{90} & $100 \% \mathrm{CP}$ & $0,73 \mathrm{a}$ & $0,27 \mathrm{a}$ & $2,72 \mathrm{a}$ & $0,28 \mathrm{a}$ & $1,02 \mathrm{a}$ & $27,20 \mathrm{~b}$ \\
& $80 \% \mathrm{CP}$ & $0,65 \mathrm{a}$ & $0,34 \mathrm{a}$ & $2,47 \mathrm{a}$ & $0,33 \mathrm{a}$ & $1,15 \mathrm{a}$ & $26,70 \mathrm{~b}$ \\
& $60 \% \mathrm{CP}$ & $0,72 \mathrm{a}$ & $0,42 \mathrm{a}$ & $2,79 \mathrm{a}$ & $0,38 \mathrm{a}$ & $1,45 \mathrm{a}$ & $34,50 \mathrm{a}$ \\
& $40 \% \mathrm{CP}$ & $0,91 \mathrm{a}$ & $0,91 \mathrm{a}$ & $1,00 \mathrm{a}$ & $0,55 \mathrm{a}$ & $2,49 \mathrm{a}$ & $29,50 \mathrm{ab}$ \\
\hline \multirow{2}{*}{120} & $100 \% \mathrm{CP}$ & $0,51 \mathrm{~b}$ & $0,74 \mathrm{a}$ & $0,69 \mathrm{a}$ & $0,32 \mathrm{a}$ & $1,24 \mathrm{a}$ & $27,07 \mathrm{~b}$ \\
& $80 \% \mathrm{CP}$ & $0,54 \mathrm{~b}$ & $0,61 \mathrm{a}$ & $0,97 \mathrm{a}$ & $0,29 \mathrm{a}$ & $1,40 \mathrm{a}$ & $26,10 \mathrm{~b}$ \\
& $60 \% \mathrm{CP}$ & $1,20 \mathrm{a}$ & $0,30 \mathrm{a}$ & $3,75 \mathrm{a}$ & $0,32 \mathrm{a}$ & $1,51 \mathrm{a}$ & $24,55 \mathrm{~b}$ \\
& $40 \% \mathrm{CP}$ & $1,02 \mathrm{a}$ & $0,32 \mathrm{a}$ & $3,18 \mathrm{a}$ & $0,39 \mathrm{a}$ & $1,34 \mathrm{a}$ & $32,75 \mathrm{a}$ \\
\hline
\end{tabular}

Em que: Médias seguidas de mesma letra iguais nas colunas não diferem entre si pelo teste de Tukey a $5 \%$ de probabilidade.

alterações estatisticamente significativas ao longo do período experimental. Os valores médios variaram aos 60 dias nas plantas com $40 \%$ e $100 \%$ $\mathrm{CP}$ de $2,33 \mathrm{mg} / \mathrm{g}$ MF a 2,67 mg/g MF, aos 90 dias de $1,0 \mathrm{mg} / \mathrm{g}$ MF a $2,72 \mathrm{mg} / \mathrm{g}$ MF e aos 120 dias de $3,19 \mathrm{mg} / \mathrm{g}$ MF a $0,69 \mathrm{mg} / \mathrm{g}$ MF.

Os teores da clorofila total e carotenoides nas folhas de Jatropha curcas não apresentaram diferenças estatísticas significativas entre as épocas e tratamentos. Os valores apresentados pelos carotenoides aos 120 dias oscilaram de 0,29 a $0,39 \mathrm{mg} / \mathrm{g}$ MF. No entanto, os carotenoides não apresentaram diferenças significativas nas três épocas de avaliação, mostrando que esses pigmentos não foram afetados pelo estresse hídrico, atuando como fotoprotetores.

Luis (2009), avaliando os teores de clorofila em plantas de Jatropha curcas aos 18 dias de diferenciação hídrica, observou uma redução de $19,7 \%$ do teor clorofila $a$ nas plantas estressadas em relação ao controle. A clorofila $b$ não apresentou diferenças significativas tanto no controle quanto no tratamento sob estresse, apresentando valores médios de 0,36 e $0,37 \mathrm{~g} / \mathrm{Kg}$ MF no controle e estresse, respectivamente.
A relação clorofila $a / b$ não apresentou diferenças significativas, porém, apresentou valores elevados nas plantas com 60 e $40 \% \mathrm{CP}$ aos 120 dias. Diferentemente de muitos autores que relatam a degradação das clorofilas como indicadores de estresse hídrico (LARCHER, 2006), ausência de nutriente no solo (CARVALHO et al., 2007) salinidade (GRACIANO et al., 2011), estudos com Jatropha curcas sobre altos níveis de irradiâncias têm demonstrado uma relativa variação das características fisiológicas (MATOS et al., 2009). Contudo, os resultados sobre o aumento ou redução dos pigmentos fotossintéticos em plantas de pinhãomanso quando submetido ao deficit hídrico ainda são escassos.

Com relação aos teores de clorofila estimados pelo índice SPAD, observou-se que, no período de 90 dias, as plantas submetidas ao deficit hídrico apresentaram aumento significativo na concentração de pigmentos fotossintéticos no tratamento $60 \%$ da $\mathrm{CP}$, quando comparadas com as do controle. Esse comportamento também foi evidenciado nas plantas a $40 \%$ da CP aos 120 dias. Embora se tenha detectado nesse mesmo tratamento aumento no teor de clorofila aos 60 dias 
de avaliação, esse acréscimo não foi significativo quando comparado com o controle. Tais aumentos verificados nas concentrações de pigmentos fotossintéticos demonstram que a espécie pinhãomanso apresenta resistência ao deficit hídrico visando potencializar o desempenho da assimilação fotossintética do $\mathrm{CO}_{2}$ das plantas para manter o seu desenvolvimento.

\section{CONCLUSÕES}

Os resultados obtidos permitem inferir que plantas de pinhão-manso conseguem manter suas atividades fisiológicas normalizadas, mesmo submetidas ao deficit hídrico, favorecendo, assim, os padrões metabólicos sem alterações que comprometam a dinâmica da espécie.

Tendo em vista que os teores de carboidratos, proteínas e aminoácidos nas partes aéreas (folhas) e subterrâneas (raízes), muito embora tenham apresentadas variações nas suas respectivas concentrações, não foram suficientes para evidenciar intolerâncias das plantas sob estresse no período de 120 dias.

\section{AGRADECIMENTO}

A primeira autora agradece à CAPES pela concessão da bolsa para a realização da presente pesquisa.

\section{REFERÊNCIAS BIBLIOGRÁFICAS}

ARRUDA F. P. et al. Cultivo de Pinhão manso (Jatropha curcas L.) como alternativa para o semi-árido nordestino. Revista Brasileira de Oleaginosas e fibrosas, Campina Grande, v. 8, p. 789-799, 2004.

AZEVEDO NETO, A. D. Aspectos fisiológicos e bioquímicos do estresse salino em plantas de milho. 2005. 149 f. Tese (Doutorado em Bioquímica) - Universidade Federal do Ceará, Fortaleza 2005.

BATES L. S. et al. Rapid determination of free proline forwater-stress studies. Plant Soil, Dordretch, v. 39, p. 205-207, 1973.

BRADFORD, M. M. A rapid and sensitive method for the quantitation of microgram quantities of protein utilizing the principle of protein-dye binding. Analytical Biochemistry, New York, v. 72, p. 248-254, 1976.

CARVALHO, A. P. F. et al. Variações sazonais nas concentrações de pigmentos e nutrientes em folhas de espécies de cerrado com diferentes estratégias fenológicas. Revista Brasileira de Botânica, v. 30, n. 1, p. 19-27, 2007.

CARVALHO, C. J. R. Respostas de plantas de Schizolobium amazonicum $[S$. parahyba var. amazonicum] E Schizolobium parahyba [Schizolobium parahybum] à deficiência hídrica. Revista Árvore, Viçosa, v. 29, p. 907-914, 2005. DUBOIS, M. et al. Colorimetric method for determination of sugars and related substances. Analytical Chemistry, Washington, v. 28, p. 350-356, 1956.

EGERT, M.; TEVINI, M. Influence of drought on some physiological parameters symptomatic for oxidative stress in leaves of chives (Allium schoenoprasum). Environmental and Experimental Botany, Holanda, v. 48, p. 43-49, 2002.

GRACIANO, E. S. A. et al. Crescimento e capacidade fotossintética da cultivar de amendoim BR 1 sob condições de salinidade. Revista Brasileira de Engenharia Agrícola e Ambiental, Campina Grande, v. 15, n. 8, p. 794-800, 2011.

HANSON, A. D. Interpreting the metabolic responses of plants to water stress. HortScience, Alexandrina, v. 5, p. 623-629, 1980.

LARCHER, W. Ecofisiologia Vegetal.. São Carlos. Ed. Rima, 2006. 531 p.

LICHETENTHALER, H. K.; BUSCHAMANN, C. Chlorophylls and Carotenoids: measurement and Characterization by UV-VIS Spectroscopy. Current Protocols in Food Analytical Chemistry, New York, p. F4:3.1-F4:3.8, 2001.

LUIS, R. M. F. C. B. Respostas de Jatropha curcas L. ao déficit hídrico, caracterização bioquímica e ecofisiológica. 2009. 62 f. Dissertação (Mestrado em Engenharia Agronômica) - Universidade Técnica de Lisboa, Lisboa, 2009.

MARTINS, M. O. Aspectos fisiológicos de nim indiano sob déficit hídrico em condições de casa de vegetação. 2008. 84 f. Dissertação (Mestrado em Botânica) - Universidade Federal Rural de Pernambuco, 2008.

MATOS, F, S. et al. Caracterização fisiológica de mudas de Jatropha curcas L. produzidas em diferentes níveis de irradiância. Revista Colombiana de Ciências Hortícolas, v. 3, n. 1, p. 126-134, 2009.

NEPOMUCENO, A. L. et al. Tolerância à seca em plantas: Mecanismos fisiológicos e moleculares. Revista Biotecnologia, Ciência e Desenvolvimento, Brasília, v. 23, p. 12-18, 2001. 
NOGUEIRA, R. J. M. C. et al. Alterações na resistência à difusão de vapor das folhas e relações hídricas em aceroleiras submetidas a déficit de água. Revista Brasileira de Fisiologia Vegetal v. 13, p. 75-87, 2001.

NOGUEIRA, R. J. M. C.; SANTOS, R. C. Alterações fisiológicas no amendoim submetido ao estresse hídrico. Revista Brasileira de Engenharia Agrícola e Ambiental, Bodocongó, v. 4, p. 41-45, 2000.

OPENSHAW, K. A review of Jatropha curcas: an oil plant of unfulfilled promise. Biomass and Bioenergy, Silver Spring, v. 19, p. 1-15, 2000.

PIMENTEL, C. A relação da planta com a água. Seropédica: Editora Universitária, 2004. 19 p.

SARKER, B. C.; HARA, M.; UEMURA, M. Proline synthesis, physiological responses and Biomas yield of eggplants during and after repetitive soil moisture stress. Scentia Horticulturae, v. 103, p. 387-402, 2005.

SATO, M. et al. A cultura do pinhão-manso (Jatropha curcas L.) uso para fins combustiveis e descrição agronômica, Revista Varia Scientia v. 7, n. 13, p. 47-62, 2009.

SATURNINO, H. M. et al. Cultura do pinhão manso (Jatropha curcas L.). Informe Agropecuário, Belo Horizonte, v. 26, n. 229, p. 44-78, 2005.

SCHOLANDER, P. F. et al. Sap pressure in vascular plants. Science, Washington, v. 148, p. 339-346, 1965.

SILVA, E. C. et al. Aspectos ecofisiológicos de dez espécies em uma área de caatinga no município de Cabaceiras, Paraíba, Brasil. Iheringia, Série Botânica, v. 59, p. 201-205, 2004.
SILVA, J. R. R. Comportamento ecofisiológico de plantas jovens de andiroba (Carapa guianensis Aubl.) sob dois regimes hídricos. 2009. 40 f. Dissertação (Mestrado em Agronomia) - Universidade Federal Rural da Amazônia, 2009.

SOUZA, C. C. et al. Avaliação de métodos de determinação de água disponível e manejo da irrigação em terra roxa sob cultivo de algodoeiro herbáceo. Revista Brasileira de Engenharia Agrícola e Ambiental, Paraíba, v. 4, p. 338-342, 2000.

SOUZA, E. B. Indicadores fisioquímicos para seleção de plantas de algodão herbáceo tolerantes à seca. 2008. 93 f. Dissertação (Mestrado em Botânica) - Universidade Federal Rural de Pernambuco, Recife, 2008.

SOUZA, J. G. et al. Fisiologia e produtividade do gergelim em solo com deficiência hídrica. Brasileira de Oleaginosas e Fibrosas, Campina Grande, v. 4, p. 163-168, 2000.

SUBBARAO, G. V. Osmotic adjustment, water relations and carbohydrate remobilization in pigeonpea under water stress. Journal of Plant Physiology, Australian, v. 157, n. 6, p. 651-659, 2000.

TAIZ, L.; ZEIGER, E. Fisiologia Vegetal. 4. ed. Porto Alegre: Artmed. 2009. 744 p.

WEATHERLEY, P. E. Studies in the water relations of the cotton plant I: the field measurements of water deficits in leaves. New Phytologist, Cambrigde, v. 49, p. 81-97, 1950.

YEMM, E. W.; COCKING, E. F. The determination of amino acidis with ninhydrin. Analyst, London, v. 80 , p. 209-213, 1955. 